\title{
Electrooxidation of phenol on carbon fibre-based anodes through continuous electrolysis of synthetic wastewater
}

\author{
Grazyna Piotrowska, Boguslaw Pierozynski* \\ University of Warmia and Mazury in Olsztyn, Department of Chemistry, Faculty of Environmental Management and \\ Agriculture, Plac Lodzki 4, 10-727 Olsztyn, Poland \\ "Corresponding authors: bogpierozynski@yahoo.ca; boguslaw.pierozynski@uwm.edu.pl
}

\begin{abstract}
This work reports on the process of phenol electrooxidation, which is carried-out through continuous electrolysis of synthetic, sodium sulphate-based wastewater. Phenol electrodegradation is examined by means of a laboratory size ( $c a .700 \mathrm{~cm}^{3}$ of working volume), poly (methyl methacrylate)-made electrolyser unit for various, carbon fibre and graphite-based anode configurations, and stainless steel cathodes, two different current-densities and concentrations of phenol in synthetically prepared wastewater solution. Proper monitoring of phenol degradation (including quantitative identification of reaction products and calculation of specific energy consumption) in wastewater is performed by means of instrumental, combined HPLC and MS technique in function of electrolysis time.
\end{abstract}

Keywords: phenol electrooxidation reaction, carbon fibre, wastewater electrolysis, High-Performance Liquid Chromatography/Mass Spectrometry analysis.

\section{INTRODUCTION}

Some industrial wastewaters (especially these produced at refineries and pharmaceutical plants) contain large amounts of phenol-based chemicals, which themselves constitute serious environmental problems ${ }^{1-9}$. One of the most attractive methods for the degradation of phenolic compounds is the process of their electrochemical oxidation. Both noble and transitional metals (for example $\mathrm{Pt}, \mathrm{Ti}, \mathrm{Sn}$ and $\mathrm{Pb}$ elements) were found to be suitable for electrodegradation of various phenolic compounds ${ }^{1,4,6,8,9-12}$. In addition, a selection of articles is available in literature on the application of graphite and carbon-based materials as anodes to carry-out electrochemical degradation of phenol. Hence, Krawczyk et al. ${ }^{13}$ have recently studied the process of phenol electrooxidation on the expanded graphite electrode along with its consequent in-situ $\mathrm{O}_{2}$-based regeneration. Similar works were published by Awad and Abuzaid ${ }^{14}$, and by Mu'azu et al. in Ref. 15, whereas Hussain et al. examined anodic oxidation of phenol on large surface-area, so-called unexpanded graphite intercalation compound ${ }^{\mathbf{1 6}}$. In addition, some other works describe phenol electrodegradation process on various forms of activated carbon anodes (see Refs. 17-19 for details). Finally, an innovative boron-doped diamond (BDD) anode was shown ${ }^{4,20,21}$ to exhibit significant catalytic properties towards electrochemical degradation of phenol in synthetically-prepared wastewaters. Although their superior catalytic properties and mechanical stability, they eventually proved to be too expensive for their practical employment in commercial wastewater treatment facilities.

This article specifically makes a follow-up of a recently published paper on phenol electrooxidation reaction (PhER) performed via continuous electrolysis of synthetic wastewater on platinized titanium and stainless steel anodes from this laboratory ${ }^{22}$. This work again is concerned with the continuous process of phenol electrodegradation, but examined on pure and catalyst-modified carbon fibre Hexcel $12 \mathrm{~K}$ tow electrodes, in comparison to the behaviour of electrographite anodes.

\section{EXPERIMENTAL}

A poly (methyl methacrylate)-made, $c a .700 \mathrm{~cm}^{3}$ of working volume, wastewater electrolysis cell employed in this work was illustrated in Fig. 1 of Ref. 22. In short, the electrolyser contained a centrally positioned, Hexcel $12 \mathrm{~K}$ AS4C: 12,000 filament tow of $7 \mu \mathrm{m}$ diameter for each filament carbon fibre (CF) or electrographite (EG, HLM) plate with a surface area of $72.0 \mathrm{~cm}^{2}$ ( $c a$. $6 \times 5 \times 0.7 \mathrm{~cm}$ with six centrally positioned openings of 0.6 $\mathrm{cm}$ diameter) single anode. Here, the following carbon fibre tow electrodes were prepared and tested:

a) as received: heat-treated anodes $(\mathrm{CF})$ in a muffle furnace at low oxygen atmosphere (for $4 \mathrm{~h}$ at $320^{\circ} \mathrm{C}$ ),

b) chemically anodized anodes $\left(\mathrm{CF}_{\mathrm{ox}}\right)$, carried out in 1:1 $\mathrm{HNO}_{3}$ (for 1 hour at room temperature) and

c) catalytically modified $\mathrm{CF}$ anodes by electrodeposition of $\mathrm{Ru}(\mathrm{CF} / \mathrm{Ru}), \mathrm{Pd}(\mathrm{CF} / \mathrm{Pd})$ and $\mathrm{Pt}(\mathrm{CF} / \mathrm{Pt})$ elements, performed from respective ruthenium and palladium chloride salts, and chloroplatinic acid hexahydrate for platinum (at cathodic current-densities of $c a .0 .2 \mathrm{~mA}$ $\mathrm{cm}^{-2}$, see Refs. 23-26 for details).

Geometrical surface area of CF tow electrodes was either 1.584 or $3,168 \mathrm{~cm}^{2}$ ( 60 or $120 \mathrm{~cm}$ in length), where Fig. 1a below presents the $\mathrm{CF}_{\mathrm{ox}}: 3.168 \mathrm{~cm}^{2}$, PTFE framemounted carbon fibre anode. On the other hand, two cathodes (stainless-steel electrodes: AISI 321: $49 \times 39 \times 2$ $\mathrm{mm}$ ) were placed at two sides of the electrolyser cell. A distance between anode and cathode was about 20 $\mathrm{mm}$ (40 $\mathrm{mm}$ between the two cathodes). Stainless steel cathodes were initially polished with emery paper down to 2000 grade, de-greased with acetone and rinsed with ultra-pure water $(18.2 \mathrm{M} \Omega \mathrm{cm}$ Millipore Q3 UV water purification system was used).

The electrolyser was operated at room temperature in a wastewater recirculation mode (at a rate of 20 $\mathrm{cm}^{3} \mathrm{~min}^{-1}$ ) by means of Gilson Minipuls 3 peristaltic pump $^{22}$. The electrolyser was galvanostatically energized by means of a laboratory $10 \mathrm{~V} / 2 \mathrm{~A}$ dc power supply, with periodic (every 30 minutes) recording of resulting voltage and current parameters. Synthetic wastewater solution 
a)

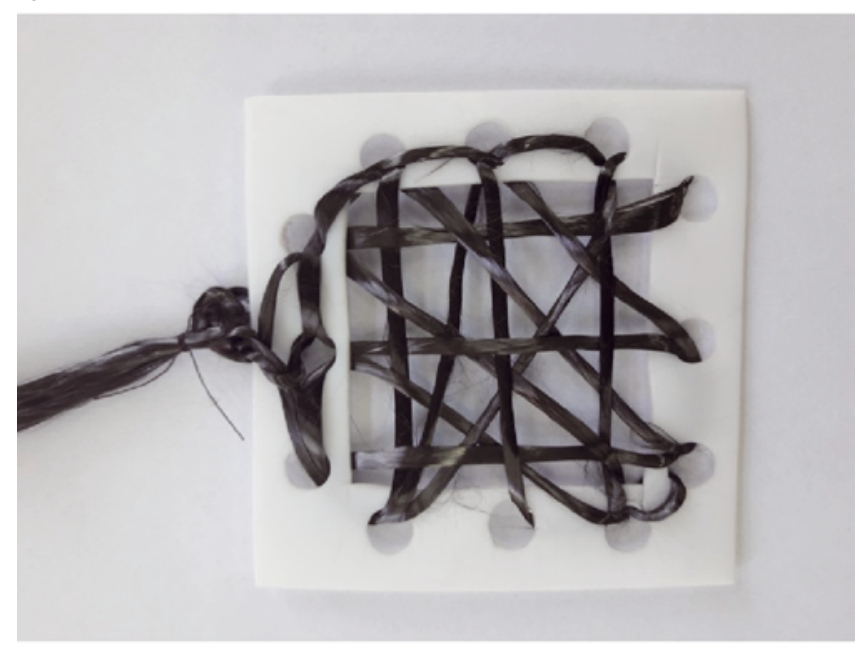

b)

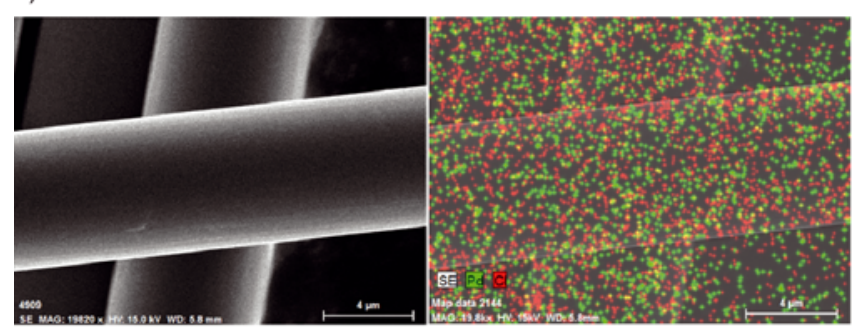

c)

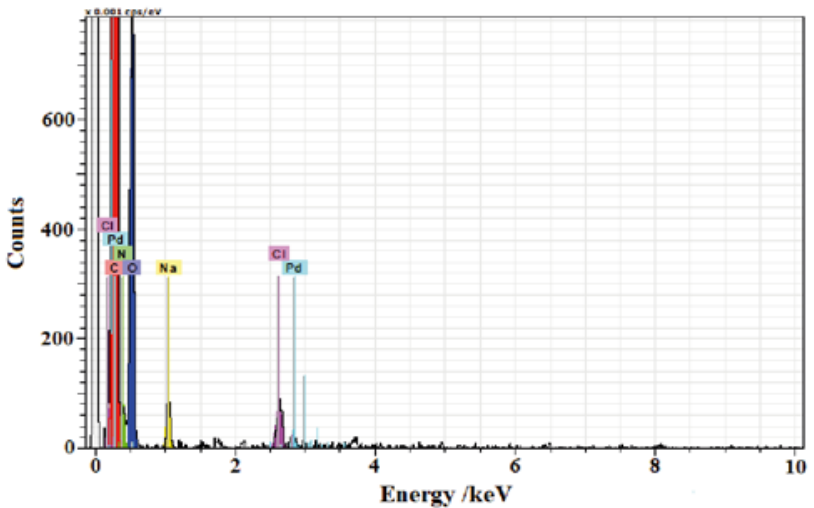

Figure 1. a) Carbon fibre-based (CFox: $3.168 \mathrm{~cm}^{2}$, PTFE frame-mounted) anode entity, employed for electrodegradation of phenol in synthetically prepared wastewater by means of the wastewater electrolyzer assembly presented in Fig. 1 of Ref. 22; b) SEM micrograph picture of Pd-modified ( $c a .10$ wt. \%) Hexcel 12K AS4C CF composite anode, taken at $19,820 \times$ magnification; c) As in (b) above, but EDX mapping

was prepared by dissolving $\mathrm{Na}_{2} \mathrm{SO}_{4}$ (0.030 M, Polish Chemical Compounds, p.a.) using Millipore ultra-pure water source with initial phenol (Sigma-Aldrich, >99\%) concentrations on the order of $1 \times 10^{-4} \mathrm{M}\left(9.4 \mathrm{mg} \mathrm{dm}^{-3}\right)$ and $1 \times 10^{-3} \mathrm{M}\left(94.1 \mathrm{mg} \mathrm{dm}^{-3}\right)$.

The process of phenol electrodegradation was examined on the following objects:

I. $2 \times$ Cathodes: SS; Anode: $\mathrm{CF}\left(1.584 \mathrm{~cm}^{2}\right) ; \mathrm{I}=100$ $\left.\mathrm{mA} ; \mathrm{pH}=7.0 ; x=5.0 \mathrm{mS} \mathrm{cm}{ }^{-1} ; \mathrm{Ph}\right]=1 \times 10^{-4} \mathrm{M}$;

II. $2 \times$ Cathodes: SS; Anode: CF/Pt (ca. 1 wt.\%) [1.584 $\left.\mathrm{cm}^{2}\right] ; \mathrm{I}=100 \mathrm{~mA} ; \mathrm{pH}=7.0 ; x=5.0 \mathrm{mS} \mathrm{cm}{ }^{-1} ;[\mathrm{Ph}]=$ $1 \times 10^{-4} \mathrm{M}$;
III. $2 \times$ Cathodes: SS; Anode: $\mathrm{CF}_{\text {ox }}\left(3.168 \mathrm{~cm}^{2}\right) ; \mathrm{I}=100$ $\mathrm{mA} ; \mathrm{pH}=7.0 ; x=5.0 \mathrm{mS} \mathrm{cm} ;[\mathrm{Ph}]=1 \times 10^{-4} \mathrm{M}$;

IV. $2 \times$ Cathodes: SS; Anode: CF/Pd (ca. 10 wt. $\%$ ) $\left[3,168 \mathrm{~cm}^{2}\right] ; \mathrm{I}=100 \mathrm{~mA} ; \mathrm{pH}=7.0 ; x=5.0 \mathrm{mS} \mathrm{cm}{ }^{-1}$; $[\mathrm{Ph}]=1 \times 10^{-4} \mathrm{M}$;

V. $2 \times$ Cathodes: SS; Anode: CF $\left(3.168 \mathrm{~cm}^{2}\right) ; \mathrm{I}=100$ $\mathrm{mA} ; \mathrm{pH}=7.0 ; x=5.0 \mathrm{mS} \mathrm{cm}{ }^{-1} ;[\mathrm{Ph}]=1 \times 10^{-4} \mathrm{M}$;

VI. $2 \times$ Cathodes: SS; Anode: $\mathrm{CF} / \mathrm{Ru}$ (ca. 10 wt. $\%$ ) $\left[3,168 \mathrm{~cm}^{2}\right] ; \mathrm{I}=100 \mathrm{~mA} ; \mathrm{pH}=7.0 ; x=5.0 \mathrm{mS} \mathrm{cm}{ }^{-1}$; $[\mathrm{Ph}]=1 \times 10^{-4} \mathrm{M}$;

VII. $2 \times$ Cathodes: SS; Anode: CF/Pd (ca. 10 wt. $\%$ ) $\left[3,168 \mathrm{~cm}^{2}\right] ; \mathrm{I}=100 \mathrm{~mA} ; \mathrm{pH}=7.0 ; x=5.0 \mathrm{mS} \mathrm{cm}{ }^{-1}$; $[\mathrm{Ph}]=1 \times 10^{-3} \mathrm{M}$;

VIII. $2 \times$ Cathodes: SS; Anode: Electrographite (72.0 $\left.\mathrm{cm}^{2}\right) ; \mathrm{I}=100 \mathrm{~mA} ; \mathrm{pH}=7.0 ; x=5.0 \mathrm{mS} \mathrm{cm}{ }^{-1} ;[\mathrm{Ph}]=$ $1 \times 10^{-4} \mathrm{M}$;

IX. $2 \times$ Cathodes: SS; Anode: Electrographite (72.0 $\left.\mathrm{cm}^{2}\right) ; \mathrm{I}=200 \mathrm{~mA} ; \mathrm{pH}=7.0 ; x=5.0 \mathrm{mS} \mathrm{cm}{ }^{-1} ;[\mathrm{Ph}]=$ $1 \times 10^{-4} \mathrm{M}$.

Primary analysis of phenol content in wastewater was performed spectrophoto-metrically with 4-aminoantipyrine ${ }^{27,28}$, where for every examined object four independent wastewater samples $\left(5,10,20\right.$ and $\left.40 \mathrm{~cm}^{3}\right)$ were collected for initial solution and after 2, 4, and 6 hours of the continuous electrolysis. Statistical analysis was performed by means of Fisher's least significant difference: LSD method $(\alpha=0.05)$. In addition, the process of phenol electrooxidation was subjected to a quantitative assessment of the reaction products/intermediates by means of the combined HPLC/MS analysis, performed on four pre-electrolyzed samples. Thus, Samples 1 and 2 refer to the object III, whereas Samples 3 and 4 to the object VIII, collected after 2 and 6 hours of continuous electrolysis, correspondingly. Furthermore, combined SEM (scanning electron microscopy)/EDX (energy dispersive $\mathrm{X}$-ray spectroscopy) analysis was carried-out for fresh Pd-modified CF anode materials by means of Merlin FE-SEM microscope (Zeiss), equipped with Bruker XFlash 5010 (with $125 \mathrm{eV}$ resolution) EDX appendix.

The analysis of phenol oxidation products was performed by means of HPLC (LC 20 Prominence, Shimadzu, Japan), combined with QTRAP 5500 mass spectrometer (AB SCIEX, Canada), equipped with an ESI ion source, triple quadrupole and ionic trap. Separation of the reaction products was carried-out by means of XBridge C18 $3.5 \mu \mathrm{m}, 150 \times 2.1 \mathrm{~mm}$ chromatographic column (Waters, Milford, MA, USA) at $45^{\circ} \mathrm{C}$ for the mobile phase flow of $0.2 \mathrm{~mL} \mathrm{~min}^{-1}$. Both qualitative and quantitative analyses were conducted based on the MRM (Multiple Reaction Monitoring) method. The quantitative analysis was performed through the application of linear calibration curves $\left(\mathrm{R}^{2}=0.994\right)$, based on a series of dilutions of respective standards.

\section{RESULTS AND DISCUSSION}

Fig. 1a below illustrates the PTFE-mounted, carbon fibre anode assembly used is this work to carry-out phenol electrodegradation. Then, Fig. 1b shows SEM micrograph picture/EDX mapping of palladium ( $c a$. 10 wt. \%)-modified carbon fibre tow anode, taken at $19,820 \times$ magnification for freshly-prepared electrode. The presence of homogeneously distributed $\mathrm{Pd}$ enti- 
ties (comparatively to Pd spikes observed in an EDX spectrum of Fig. 1c) could be observed in the EDX mapping illustrated in Fig. 1b. Average quantities of the deposited $\mathrm{Pd}, \mathrm{Ru}$ and $\mathrm{Pt}$ catalysts on the carbon fibre substrate were evaluated on the order of $10.0 \mathrm{wt} . \%$ (for $\mathrm{Pd}$ and $\mathrm{Ru}$ ) and $1.0 \mathrm{wt} . \%$ for $\mathrm{Pt}$ by means of a weighing method, where SEM-approximated palladium grain size value came to $10.0 \pm 1.2 \mathrm{~nm}$, see Ref. 35 in [26] for information on the respective procedure (details on the $\mathrm{Ru}$ and $\mathrm{Pt}$ average particle size are not presented in this work).

The effect of electrolysis time on phenol content for synthetically-prepared wastewater, examined for the electrolyser's configurations denoted as $\mathbf{I}$ and $\mathbf{V}$ for an initial phenol concentration of $1 \times 10^{-4} \mathrm{M}\left(9.4 \mathrm{mg} \mathrm{dm}^{-3}\right)$ is illustrated in Figs. 2a and 2b. The configurations I and $\mathbf{V}$ refer to the system having two stainless steel-made cathodes, a CF made anode entity with dc current setting of $100 \mathrm{~mA}$ (anodic current-density of: $\mathrm{j}_{\mathrm{A}}=0.06$ and
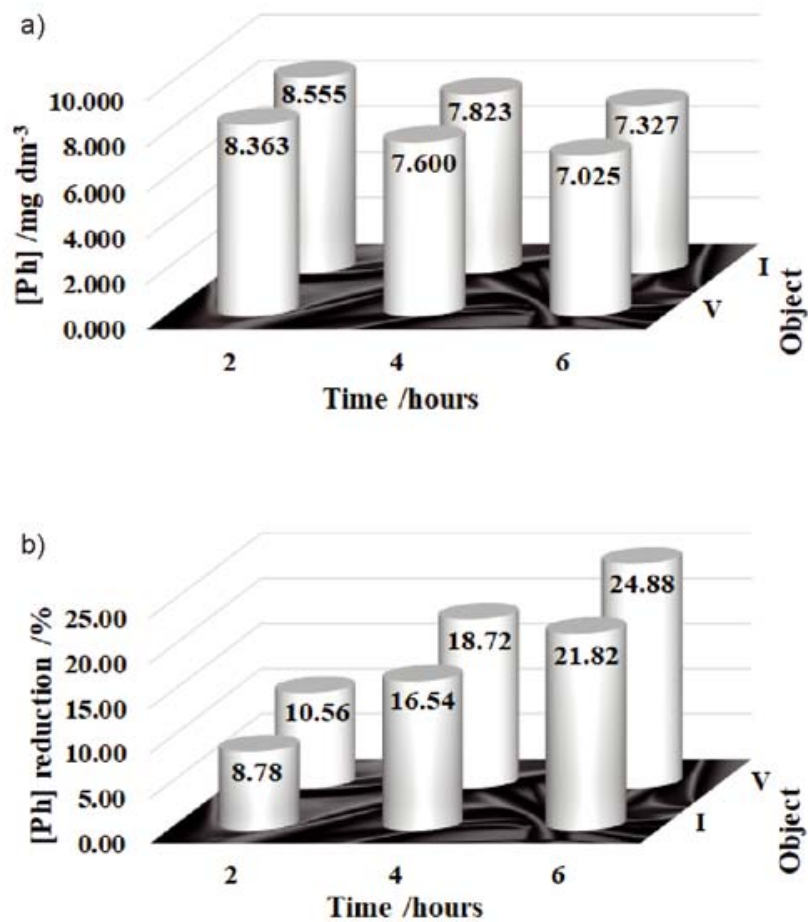

Figure 2. a) Influence of electrolysis time and surface area for as received Hexcel $12 \mathrm{~K}$ AS4C CF anode on the phenol content in synthetic wastewater for objects denoted as $\mathbf{I}$ and $\mathbf{V}$ (initial phenol concentration: $\left.1 \times 10^{-4} \mathrm{M}\right)$; b) As above, but with respect to \% reduction of initial phenol concentration
$0.03 \mathrm{~mA} \mathrm{~cm}^{-2}$ for the objects $\mathbf{I}$ and $\mathbf{V}$, respectively), $\mathrm{pH}$ $=7.0$ and $\mathrm{C}=5.0 \mathrm{mS} \mathrm{cm}{ }^{-1}$.

Thus, six hours of continuous electrolysis, carried-out on the large surface area carbon fibre anode resulted in significant diminution of phenol content in wastewater, from an initial value of 9.4 to about $7.0 \mathrm{mg} \mathrm{dm}^{-3}$, at the expense of $2.5 \times 10^{-3} \mathrm{KWh}$ of electrical energy (Table 1 ). The latter could be translated to $c a .25 \%$ reduction of initial phenol concentration (see Fig. 2b). Further and significant improvement of electrocatalytic (PhER) properties of the Hexcel $12 \mathrm{~K}$ carbon fibre anode material was achieved through the process of surface chemical oxidation (performed in $\mathrm{HNO}_{3}$ solution), where under analogous experimental conditions the concentration of phenol in wastewater dropped to $5.653 \mathrm{mg} \mathrm{dm}^{-3}$ ( $c a$. $40 \%$ phenol concentration reduction) after six hours of
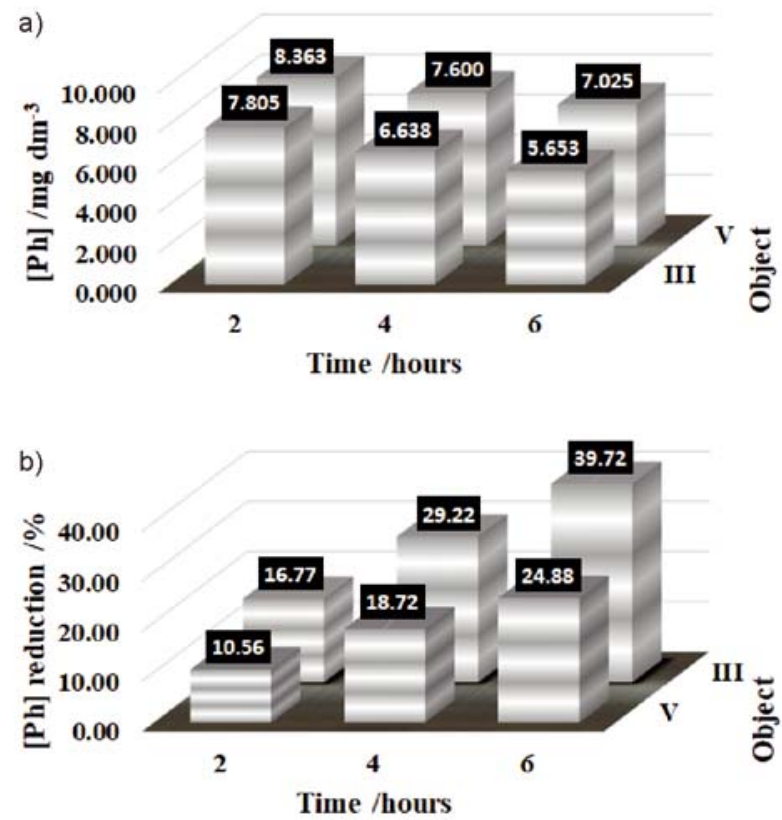

Figure 3. a) Influence of electrolysis time and surface oxidation for Hexcel $12 \mathrm{~K}$ AS4C CF anode on the phenol content in synthetic wastewater for objects denoted as III and $\mathbf{V}$ (initial phenol concentration: $1 \times 10^{-4} \mathrm{M}$ ); b) As above, but with respect to $\%$ reduction of initial phenol concentration.

constant electrolysis (see object III in Figs. 3a and 3b, correspondingly).

On the other hand, Figs. 4 and 5 illustrate the effect of catalytic: Pd and Ru (Fig. 4), and Pt (Fig. 5) modifications of the CF tow surface on its phenol elec-

Table 1. Average current and voltage parameters, and energy consumption levels, recorded upon continuous, 6-hour electrolysis of phenol-based synthetic wastewater

\begin{tabular}{|l|c|c|c|}
\hline Object & $\begin{array}{c}\text { Current } \\
{[\mathrm{mA}]}\end{array}$ & $\begin{array}{c}\text { Voltage } \\
{[\mathrm{V}]}\end{array}$ & $\begin{array}{c}\text { Consumed energy } \\
{[\mathrm{KWh}]}\end{array}$ \\
\hline $\mathrm{I}$ & 104 & 4.09 & $2.5 \times 10^{-3}$ \\
\hline $\mathrm{II}$ & 107 & 4.04 & $2.6 \times 10^{-3}$ \\
\hline $\mathrm{III}$ & 105 & 3.74 & $2.3 \times 10^{-3}$ \\
\hline $\mathrm{IV}$ & 106 & 3.69 & $2.3 \times 10^{-3}$ \\
\hline $\mathrm{V}$ & 108 & 3.88 & $2.5 \times 10^{-3}$ \\
\hline $\mathrm{VI}$ & 109 & 3.50 & $2.3 \times 10^{-3}$ \\
\hline $\mathrm{VII}$ & 109 & 3.70 & $2.4 \times 10^{-3}$ \\
\hline $\mathrm{VIII}$ & 115 & 3.47 & $2.4 \times 10^{-3}$ \\
\hline $\mathrm{IX}$ & 209 & 4.09 & $5.1 \times 10^{-3}$ \\
\hline
\end{tabular}




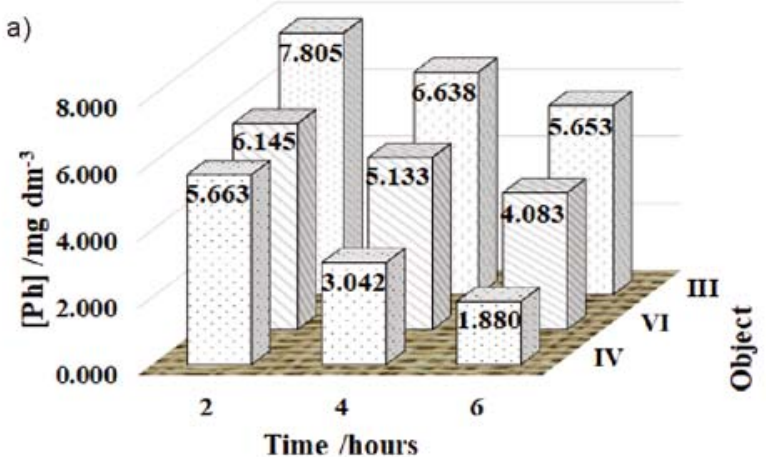

b)

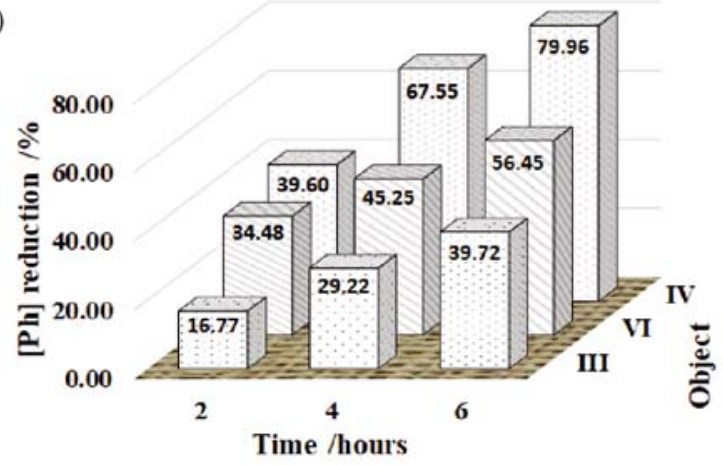

Figure 4. a) Influence of electrolysis time and $\mathrm{Pd}$ (or $\mathrm{Ru}$ )-modification (ca. $10 \mathrm{wt} \% \mathrm{Pd}$ or $\mathrm{Ru}$ ) for Hexcel $12 \mathrm{~K}$ AS4C CF anode on the phenol content in synthetic wastewater for objects denoted as III, IV and VI (initial phenol concentration: $1 \times 10^{-4} \mathrm{M}$ ); b) As above, but with respect to \% reduction of initial phenol concentration

a)

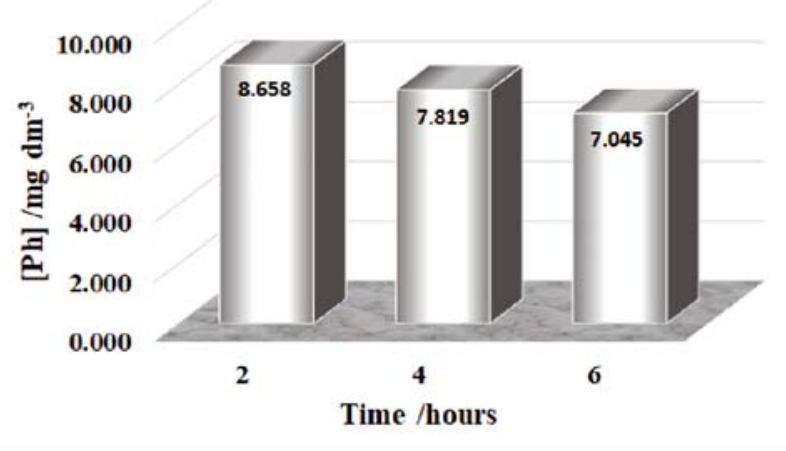

b)

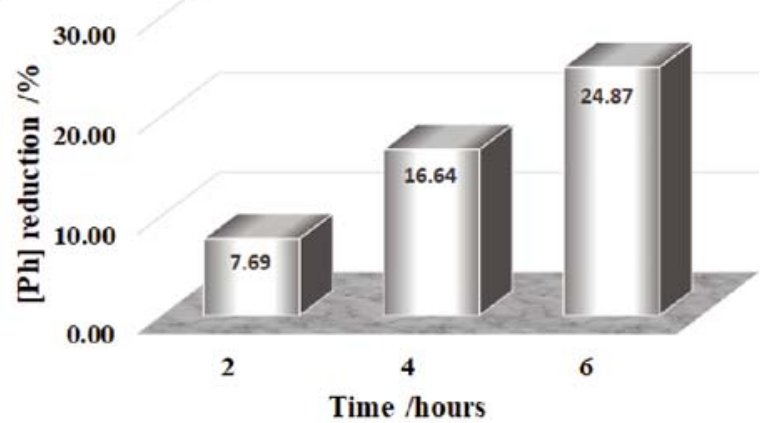

Figure 5. a) Influence of electrolysis time and Pt-modification (ca. $1 \mathrm{wt} \%$ ) for Hexcel 12K AS4C CF anode on the phenol content in synthetic wastewater for object denoted as II (initial phenol concentration: $1 \times 10^{-4}$ $\mathrm{M})$; b) As above, but with respect to $\%$ reduction of initial phenol concentration trodegradation activity. As compared to the baseline, surface-oxidized CF anode (object III), both palladium (object IV) and ruthenium (object VI)-modified (at ca. 10 wt.\%) carbon fibre composite electrodes exhibited considerable enhancement of the PhER activity, where for the Pd-activated anode this change was indeed radical (compare the remaining $[\mathrm{Ph}]=1.880 \mathrm{mg} \mathrm{dm}^{-3}$ and $c a .80 \%$ reduction of initial [Ph] with those of 5.653 $\mathrm{mg} \mathrm{dm}{ }^{-3}$, and ca. $40 \%$ of $[\mathrm{Ph}]$ depletion, recorded in Figs. $4 \mathrm{a}$ and $4 \mathrm{~b}$, respectively. In contrast, for platinum-modified CF (object II) tow electrode (1 wt.\% Pt for the CF geometrical surface area of $\left.1,584 \mathrm{~cm}^{2}\right)$, the $[\mathrm{Ph}]$ in wastewater reached $7.045 \mathrm{mg} \mathrm{dm}^{-3}$ ( $\mathrm{ca} .25 \%$ phenol concentration reduction) after six hours of electrolysis (Figs. 5a and 5b). This result is almost identical to that produced on unmodified carbon fibre, but having double electrochemically active surface area (e.g. see object $\mathbf{V}$ in Figs. 2a and 2b). Finally, for fundamentally increased phenol concentration from $10^{-4} \mathrm{M}\left(9.4 \mathrm{mg} \mathrm{dm}^{-3}\right)$ to $10^{-3}$ $\mathrm{M}\left(94.1 \mathrm{mg} \mathrm{dm}^{-3}\right)$, the process of anodic electrooxidation of phenol becomes considerably restrained. Thus, after 6 hours of phenol electrodegradation carried-out on the Pd-activated CF tow electrode (object VII) its concentration in wastewater dropped to about $60.1 \mathrm{mg}$ $\mathrm{dm}^{-3}$ (only ca. 36\% concentration reduction), at the expense of $2.4 \times 10^{-3} \mathrm{KWh}$ of consumed energy (see Figs. $6 \mathrm{a}$ and $6 \mathrm{~b}$, respectively). Significant impediment of the PhER recorded upon a 10 -fold increase of initial phenol concentration most likely results from the fact that under harsh experimental conditions, reactive catalyst surface could become subjected to self-inhibition effects, due to extended formation of polymeric film(s) on the electrode surface ${ }^{6,29}$.

Furthermore, Figs. $7 \mathrm{a}$ and $7 \mathrm{~b}$ below present the influence of electrolysis time and imposed current-density parameter for HLM electrographite anode plate on the concentration of phenol in synthetically-prepared wastewater solution. Hence, for an anodic current-intensity of $100 \mathrm{~mA}$ ( $c a .1 .4 \mathrm{~mA} \mathrm{~cm}^{-2}$ ), the concentration of phenol in wastewater dropped from the initial value of 9.4 to about $3.1 \mathrm{mg} \mathrm{dm}^{-3}$ ( $\mathrm{ca} .67 \%$ concentration reduction) after six hours of uninterrupted electrolysis (see object VIII in Figs. 7a and 7b). In contrast, for doubled current-density $\left(2.8 \mathrm{~mA} \mathrm{~cm}{ }^{-2}\right)$, the wastewater purification system responded in significantly reduced efficiency of the PhER, i.e. $3.5 \mathrm{mg} \mathrm{dm}^{-3}$ and $62.5 \%$ parameters for analogous experimental conditions (object IX in Figs. $7 \mathrm{a}$ and $7 \mathrm{~b}$ ). The latter effect most likely results from a combination of parasitic anodic oxygen evolution reaction (OER) and intensified formation of the mentioned polymeric layer on the electrographite surface.

In brief, out of all studied carbon fibre-based anodes, Pd-modified CF tow electrode proved to be the most effective anode to carry-out the process of phenol electrodegradation in sulphate-based synthetic wastewater (object IV). However, it should be stressed that employment of surface-oxidized CF tow anode (object III) is the most cost-effective solution to this problem. Here, simple $\mathrm{CF}$ oxidation (compared to unmodified CF anode) allows to increase the reduction $\%$ of phenol concentration in the electrolyser cell by $1.6 \times$ upon two, as well as after six hours of continuous electrolysis (see Fig. 3b). Also, it is rather very difficult to compare significantly higher 
a)

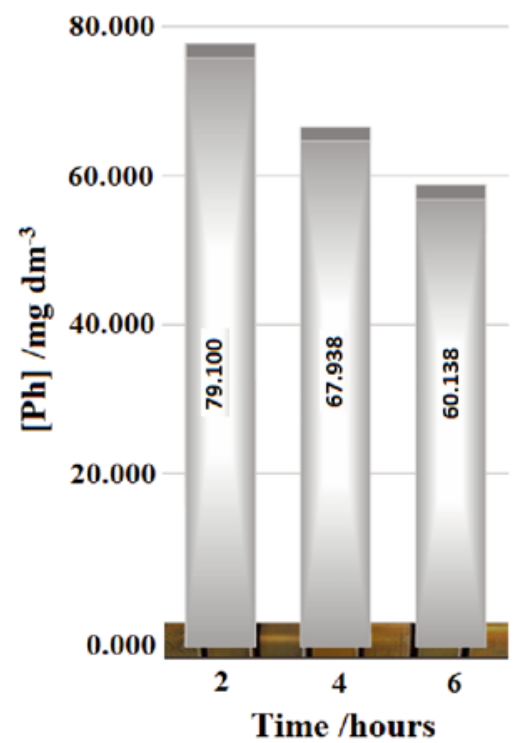

b)

40.00

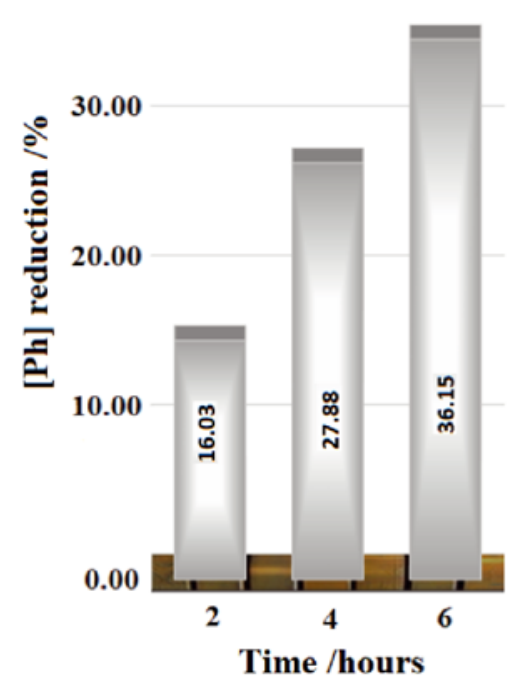

Figure 6. a) Influence of electrolysis time for Pd-modified (ca. $10 \mathrm{wt} . \%$ ) Hexcel 12K AS4C CF anode on the phenol content in synthetic wastewater for object denoted as VII (initial phenol concentration: $1 \times 10^{-3} \mathrm{M}$ ); b) As above, but with respect to \% reduction of initial phenol concentration

PhER performance exhibited by the electrographite plates with that of the CF tow anodes, due to a radical difference in electrochemically active surface area for these materials. In fact, it is also possible that a complex CF tow entity enables substantial aggregation of oxygen bubbles generated upon the parasitic oxygen evolution reaction. At the same time, the surface of the electrographite plate could contain significant microporosity, something which would apparently significantly extend its electrochemically active surface beyond that of the geometrical area.

In addition, all examined objects (upon 6 hours of continuous electrolysis) exhibited similar levels of energy consumption, on the order of $2.4 \times 10^{-3} \mathrm{KWh}$ (except for the object denoted as IX: $5.1 \times 10^{-3} \mathrm{KWh}$, see Table 1 ). Then, for the two most efficient CF-based configurations (objects III and IV), the energy requirements would ap- a)

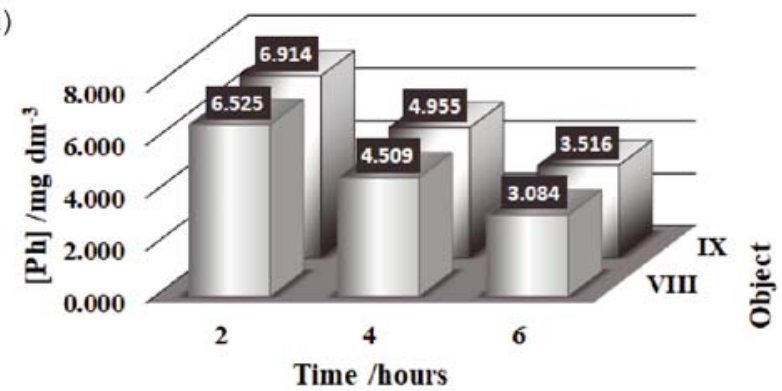

b)

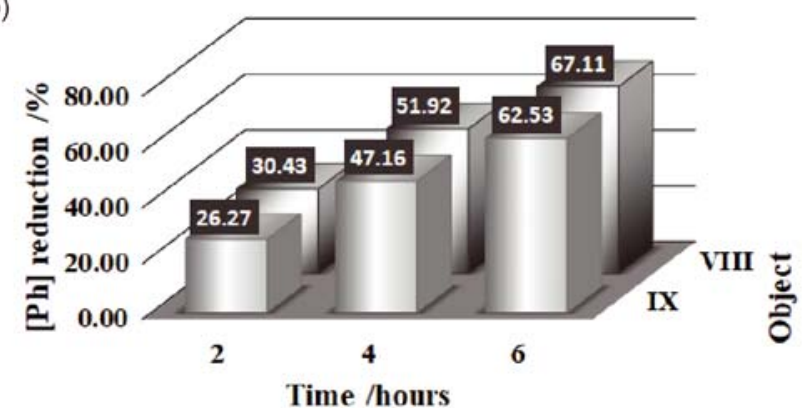

Figure 7. a) Influence of electrolysis time and imposed anodic current-density for HLM electrographite anode plate on the phenol content in synthetic wastewater for objects denoted as VIII and IX (initial phenol concentration: $1 \times 10^{-4} \mathrm{M}$ ); b) As above, but with respect to $\%$ reduction of initial phenol concentration

proach 480 and $614 \mathrm{kWh}$ (object III), and 205 and 306 kWh (object IV) in order to electrochemically degrade $1 \mathrm{~kg}$ of phenol, based on the calculations carried-out for 2 and 6 hours of continuous electrolysis, respectively. It is then evident that the efficiency of the PhER becomes considerably reduced along with a progress of the electrolysis process. The latter is a partial result of surface contamination by electrosorbed phenol oxidation by-products. Similar articles on the process of electrocatalytic degradation of phenol were published by $\mathrm{Li}$ et al. [8] ( $\mathrm{Ti} / \mathrm{RuO}_{2}-\mathrm{Pt}$ and $\mathrm{Ti} / \mathrm{IrO}_{2}-\mathrm{Pt}$ anodes), Dos Santos et al. ${ }^{12}$ ( $\mathrm{Ti} / \mathrm{RuO}_{2}$ anode), Mu'azu et al. ${ }^{15}$ (graphite anodes) and by Berenguer et al. ${ }^{30}$ ( $\mathrm{Pt} / \mathrm{Ru}$-doped Ti/SnO ${ }_{2}-\mathrm{Sb}$ anodes). Although some of the recorded there energy levels for the removal of $1 \mathrm{~kg}$ of phenol were somewhat lower than those presented in this work, it should be stressed that the reported experimental electrolysis works in Refs. 12 and 30 were carried-out in highly-conductive electrolytes and thus under unrealistic for wastewater plant conditions $\left(0.34 \mathrm{M} \mathrm{NaCl}^{12}\right.$ and $\left.0.5 \mathrm{M} \mathrm{NaOH}^{30}\right)$. In this work, sodium chloride was not used as a base of supporting solution in order to avoid the formation of chlorinated intermediates and electrolysis by-products. However, it is also worth mentioning that the reported here (on carbon fibre-based anodes), necessary amounts of electrical energy for the destruction of $1 \mathrm{~kg}$ of phenol are significantly lover that those recently presented in Ref. 22 for platinized titanium and stainless steel anode configurations.

Furthermore, combined HPLC/MS investigation was carried-out on four pre-electrolyzed samples: Sample 1: object III, $\mathrm{t}=2$ hours; Sample 2: object III, $\mathrm{t}=6$ hours; Sample 3: object VIII, $\mathrm{t}=2$ hours; Sample 4: object VIII, $\mathrm{t}=6$ hours, about 24 hours after completion 
of the electrolysis process. Hence, electrooxidation of phenol led to the formation of a series of intermediates, including: p-benzoquinone, maleic acid and hydroquinone (see respective chromatograms in Fig. 8 below). It should be noted here that oxalic acid was not instrumentally detected due to its low molecular mass. In addition, Table 2 presents quantitative HPLC/MS evaluation of phenol and maleic acid for Samples 1 through 4. Thus, all electrolyzed wastewater samples contained very small amounts of phenol (3.0-8.0) $\times 10^{-5} \mathrm{M}$ and rather traces of maleic acid $\left(\mathrm{ca} \cdot 10^{-7} \mathrm{M}\right)$. On the other hand, average concentrations of instrumentally derived values for hydroquinone and p-benzoquinone species were rather very qualitative and came on the order of $10^{-4}$ to $10^{-3}$ $\mathrm{M}$ (compare with the respective phenol degradation rates and the concentrations of phenol electrooxidation intermediates shown in Refs. 16 and 17).

\section{CONCLUSIONS}

All carbon fibre-based, as well as graphite anodes exhibited significant activity in electro-degradation of phenol, performed via continuous electrolysis of synthetically made, sulphate-based wastewater. The laboratory made electrolysis setup for the two most effective carbon fibre-based anode configurations (and stainless steel cathodes) would require about $480 \mathrm{kWh}$ (for chemically oxidized CF) and only $205 \mathrm{kWh}(10.0$ wt.\% palladium-activated $\mathrm{CF}$ ) of electrical energy in order to degrade $1 \mathrm{~kg}$ of phenol, based on the 2-hour electrolysis process. Such energy demand is in-line with similar values presented in many other research papers on this subject. Surface contamination by electrosorbed phenol oxidation by-products is believed to be responsible for a recorded efficiency drop in time for phenol electrooxidation reaction. In addition, operation of PhER anodes at increased anodic current-density most likely results in intensification of a parasitic, anodic oxygen evolution reaction.
Principal phenol electrooxidation products include hydroquinone and p-benzoquinone, where the presence of maleic acid on the order of $\sim 10^{-7} \mathrm{M}$ concentration (after 6 hours of continuous wastewater electrolysis) might suggest that further and quantitative, steady degradation of aromatic ring to produce oxalic acid and finally carbon dioxide (see Fig. 9) could take very long time. Hence, the most effective way of electrochemical degradation

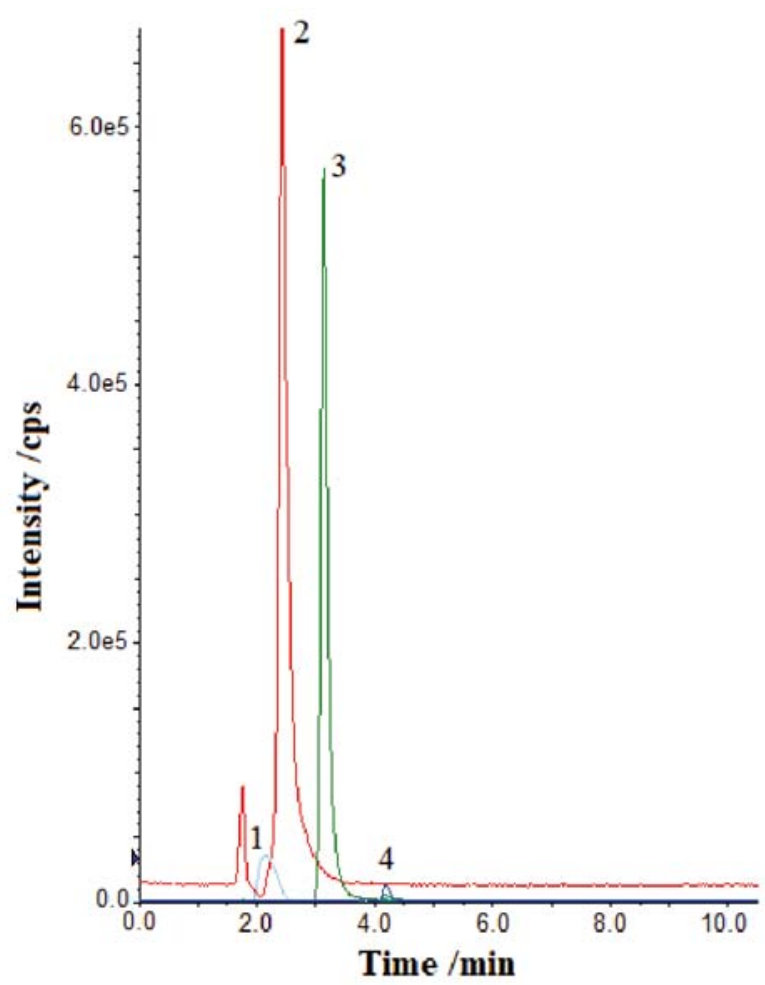

Figure 8. HPLC chromatograms recorded for phenol-based, electrolyzed synthetic wastewater (Sample 2) exhibiting phenol and its electrooxidation by-products, namely: 1 - p-benzoquinone, 2 - maleic acid, 3 hydroquinone and $4-$ phenol

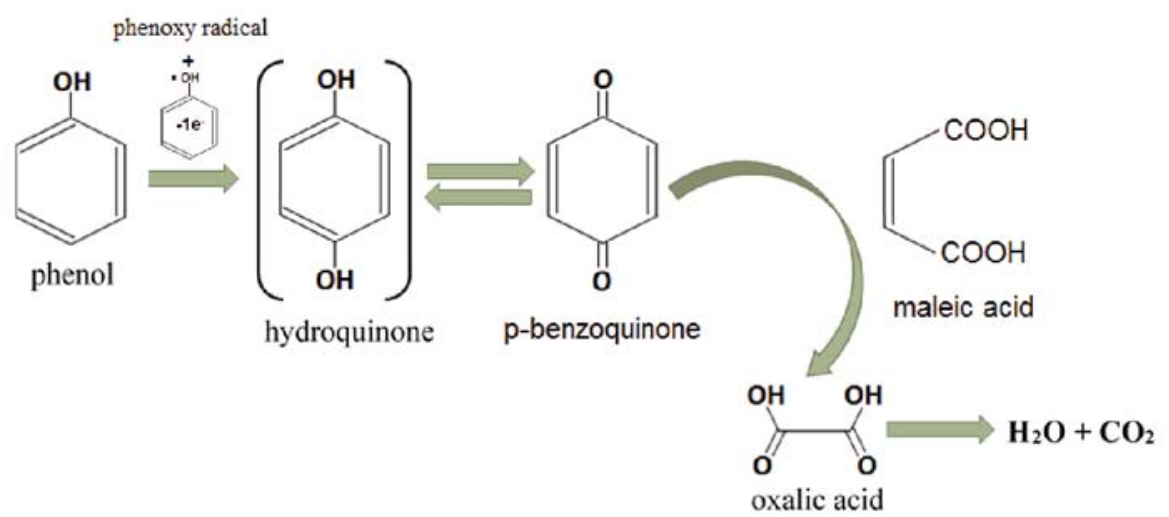

Figure 9. Schematic diagram of phenol electro-degradation process

Table 2. Quantitative evaluation of PhER products generated from phenol-based synthetic wastewater by means of HPLC/MS analysis

\begin{tabular}{|l|c|c|c|c|}
\hline \multicolumn{5}{|c|}{$\begin{array}{c}\text { Average content of PhER products } \\
{\left[\mathrm{mol} \mathrm{dm}^{-3}\right]}\end{array}$} \\
\hline Sample & Phenol & Maleic acid & Hydroquinone & p-benzoquinone \\
\hline 1 & $8.0 \times 10^{-5}$ & $5.0 \times 10^{-8}$ & & \multirow{2}{*}{$\sim 10^{-4}-10^{-3}$} \\
\hline 2 & $6.0 \times 10^{-5}$ & $1.5 \times 10^{-7}$ & & \\
\hline 3 & $7.0 \times 10^{-5}$ & $2.0 \times 10^{-7}$ & \\
\hline 4 & $3.0 \times 10^{-5}$ & $1.9 \times 10^{-7}$ & \\
\hline
\end{tabular}


of phenol seems to be a continuous process carried-out in a recirculation mode. However, further examination (including time-dependent analysis of hydroquinone/pbenzoquinone degradation process) is necessary in order to optimize its operational parameters.

\section{LITERATURE CITED}

1. Torres, R.A., Torres, W., Peringer, P. \& Pulgarin, C. (2003). Electrochemical degradation of $p$-substituted phenols of industrial interest on Pt electrodes. Attempt of a structure-reactivity relationship assessment. Chemosphere 50, 97-104. DOI: 10.1016/S0045-6535(02)00487-3.

2. Rajkumar, D. \& Palanivelu, K. (2004). Electrochemical treatment of industrial wastewater. J. Hazard. Mater. B113, 123-129. DOI: 10.1016/j.jhazmat.2004.05.039.

3. Pirvu, C., Banu, A., Radovici, O. \& Marcu, M. (2008). Application of electrochemical impedance spectroscopy (EIS) to study of phenolic films. Rev. Roum. Chim. 53(11), 1007-1015.

4. Tasic, Z., Gupta, V.K. \& Antonijevic, M.M. (2014). The mechanism and kinetics of degradation of phenolics in wastewaters using electrochemical oxidation. Int. J. Electrochem. Sci. 9, 3473-3490.

5. Yang, X., Kirsch, J., Fergus, J. \& Simonian, A. (2013). Modeling analysis of electrode fouling during electrolysis of phenolic compounds. Electrochim. Acta 94, 259-268. DOI: 10.1016/j.electacta.2013.01.019.

6. Li, X., Cui, Y., Feng, Y., Xie, Z. \& Gu, J. (2005). Reaction pathways and mechanisms of the electrochemical degradation of phenol on different electrodes. Water Res. 39, 1972-1981. DOI: 10.1016/j.watres.2005.02.021.

7. Feng, Y.J. \& Li, X.Y. (2003). Electro-catalytic oxidation of phenol on several metal-oxide electrodes in aqueous solution. Water Res. 37, 2399-2407. DOI: 10.1016/S0043-1354(03)00026-5.

8. Li, M., Feng, C., Hu, W., Zhang, Z. \& Sugiura, N. (2009). Electrochemical degradation of phenol using electrodes of $\mathrm{Ti}$ / $\mathrm{RuO}_{2}-\mathrm{Pt}$ and $\mathrm{Ti} / \mathrm{IrO}_{2}$-Pt. J. Hazard. Mater. 162, 455-462. DOI: 10.1016/j.jhazmat.2008.05.063.

9. Zhang, C., Jiang, Y., Li, Y., Hu, Z., Zhou, L. \& Zhou, M. (2013).Three-dimensional electrochemical process for wastewater treatment: A general review. Chem. Eng. J. 228, 455-467. DOI: 10.1016/j.cej.2013.05.033.

10. Comninellis, Ch. \& Pulgarin, C. (1993). Electrochemical oxidation of phenol for wastewater treatment using $\mathrm{SnO}_{2}$ anodes. J. Appl. Electrochem. 23, 108-112.

11. Arslan, G., Yazici, B. \& Erbil, M. (2005). The effect of $\mathrm{pH}$, temperature and concentration on electrooxidation of phenol. J. Hazard. Mater. B124, 37-43. DOI: 10.1016/j. jhazmat.2003.09.015.

12. Dos Santos, I.D., Afonso, J.C. \& Dutra, A.J.B. (2011). Electrooxidation of phenol on a $\mathrm{Ti} / \mathrm{RuO}_{2}$ anode: Effect of some electrolysis parameters. J. Braz. Chem. Soc. 22(5), 875-883.

13. Krawczyk, P., Rozmanowski, T., Gurzęda, B. \& Osińska, M. (2016). Process of phenol electrooxidation on the expanded graphite electrode accompanied by the in-situ anodic regeneration. J. Electroanal. Chem. 775, 228-234. DOI: 10.1016/j. jelechem.2016.06.010.

14. Awad, Y.M. \& Abuzaid, N.S. (1999). Electrochemical oxidation of phenol using graphite anodes. Sep. Sci. Technol. 34(4), 699-708.

15. Mu'azu, N.D., Al-Yahya, M., Al-Haj-Ali, A.M. \& AbdelMagid, I.M. (2016). Specific energy consumption reduction during pulsed electrochemical oxidation of phenol using graphite electrodes. J. Environ. Chem. Eng. 4, 2477-2486. DOI: 10.1016/j.jece.2016.04.026.

16. Hussain, S.N., Roberts, E.P.L., Asghar, H.M.A., Campen, A.K. \& Brown, N.W. (2013). Oxidation of phenol and the adsorption of breakdown products using a graphite adsorbent with electrochemical regeneration. Electrochim. Acta 92, 20-30. DOI: 10.1016/j.electacta.2013.01.020.

17. Jin, P., Chang, R., Liu, D., Zhao, K., Zhang, L. \& Ouyang, Y. (2014). Phenol degradation in an electrochemical system with $\mathrm{TiO}_{2}$ /activated carbon fiber as electrode. J. Environ. Chem. Eng. 2, 1040-1047. DOI: 10.1016/j.jece.2014.03.023.

18. Duan, F., Li, Y., Cao H., Wang, Y., Crittenden, J.C. \& Zhang, Y. (2015). Activated carbon electrodes: Electrochemical oxidation coupled with desalination for wastewater treatment. Chemosphere 125, 205-211. DOI: 10.1016/j.chemosphere.2014.12.065.

19. Hammani, H., Boumya, W., Laghrib, F., Farahi, A., Lahrich, S., Aboulkas, A. \& El Mhammedi, M.A. (2017). Electrocatalytic effect of $\mathrm{Al}_{2} \mathrm{O}_{3}$ supported onto activated carbon in oxidizing phenol at graphite electrode. Mater. Today Chem. 3, 27-36. DOI: 10.1016/j.mtchem.2017.01.002.

20. Britto-Costa, P.H. \& Ruotolo, L.A.M. (2012). Phenol removal from wastewaters by electrochemical oxidation using boron doped diamond (BDD) and $\mathrm{Ti} / \mathrm{Ti}_{0.7} \mathrm{Ru}_{0.3} \mathrm{O}_{2} \mathrm{DSA}^{\circledR}$ electrodes. Braz. J. Chem. Eng. 29(4), 763-773.

21. Jarrah, N. \& Mu'azu, N.D. (2016). Simultaneous electrooxidation of phenol, $\mathrm{CN}^{-}, \mathrm{S}^{2-}$ and $\mathrm{NH}_{4}{ }^{+}$in synthetic wastewater using boron doped diamond anode. J. Environ. Chem. Eng. 4, 2656-2664. DOI: 10.1016/j.jece.2016.04.011.

22. Piotrowska, G. \& Pierozynski, B. (2017). Electrodegradation of phenol through continuous electrolysis of synthetic wastewater on platinized titanium and stainless steel anodes. Int. J. Electrochem. Sci. 12, 4444-4455. DOI: 10.20964/2017.05.74.

23. Pierozynski, B. \& Mikolajczyk, T. (2012). Hydrogen evolution reaction at $\mathrm{Ru}$-modified carbon fibre in $0.5 \mathrm{M} \mathrm{H}_{2} \mathrm{SO}_{4}$. Int. J. Electrochem. Sci. 7, 9697-9706.

24. Pierozynski, B. (2013). Electrooxidation of ethanol on Pd-modified carbon fibre tow material. Int. J. Electrochem. Sci. 8, 634-642.

25. Pierozynski, B. (2013). Hydrogen evolution reaction at Pd-modified carbon fibre and nickel-coated carbon fibre materials. Int. J. Hydrogen Energy 38, 7733-7740. DOI: 10.1016/j. ijhydene.2013.04.092.

26. Pierozynski, B. \& Mikolajczyk, T. (2017). Enhancement of ethanol oxidation reaction on $\mathrm{Pt}(\mathrm{PtSn})$-activated nickel foam through in situ formation of nickel oxy-hydroxide layer. Electrocatalysis 8, 252-260. DOI: 10.1007/s12678-017-0362-1.

27. Dolatto, R.G., Messerschmidt, I., Pereira, B.F., Silveira, C.A.P. \& Abate, G. (2012). Determination of phenol and $o$-cresol in soil extracts by flow injection analysis with spectrophotometric detection. J. Braz. Chem. Soc. 23 (5), 970-976.

28. Cun-guang, Y. (1998). Progress of optical determination for phenolic compounds in sewage. J. Environ. Sci. 10(1), 76-86.

29. Al-Maznai, H. \& Conway, B.E. (2001). Auto-inhibition effects in anodic oxidation of phenols for electrochemical waste-water purification. J. Serb. Chem. Soc. 66(11-12), 765-784.

30. Berenguer. R., Sieben, J.M., Quijada, C. \& Morallon, E. (2016). Electrocatalytic degradation of phenol on Pt- and Rudoped $\mathrm{Ti} / \mathrm{SnO}_{2}-\mathrm{Sb}$ anodes in an alkaline medium. Appl. Catal. B: Environ. 199, 394-404. DOI: 10.1016/j.apcatb.2016.06.038. 